\title{
CLINICAL OBSERVATIONS ON THE PROPHYLAXIS OF OPHTHALMIA NEONATORUM*
}

\author{
BY \\ IDA MANN \\ Perth, Western Australia
}

THE following precepts concerning inflammation of the eyes of the newborn are taught to all students:

(1) Purulent conjunctivitis affecting newborn babies is not invariably due to the gonococcus but may be caused by streptococci, staphylococci, or even $B$. coli and $B$. proteus.

(2) Blindness from this cause in England has been reduced from approximately 25 per cent. of all blind children in 1920 to 9 per cent. in 1940.

(3) This improvement began when the use of the Crédé method of prophylaxis with silver nitrate became universal in England.

(4) Silver nitrate is superior to other antiseptics because it is non-specific, and because it acts in two ways: by precipitating as a thin film of silver chloride on the surface of the conjunctiva, mechanically entangling all organisms, and by producing a non-specific inflammatory reaction in the sub-conjunctival tissue, leading to the formation of the lymphoid layer earlier than it would normally appear and so strengthening the resistance of the eye to infection.

The drop in the incidence of ophthalmia neonatorum has however almost coincided with the discovery of the use of the antibiotic penicillin in the treatment of gonorrhoea and pyogenic infections in general, so that, not only has the incidence of gonorrhoea fallen, but also, should a gonorrhoeal ophthalmia develop, its rapid cure is always possible. It therefore seems time to take stock of our position with regard to the necessity or otherwise of prophylactic treatment of the eyes of newborn babies.

This question is being debated all over the world, and no universal point of view is possible, since the incidence of gonorrhoea and the availability of treatment of this and of ophthalmia neonatorum vary from country to country. It therefore seems desirable to collect local data and to give local rulings for the present on the best procedure.

\section{Standard Practice in Various Countries}

United States of America.-There is no standard procedure, each State having its own code of rules for midwives. In some States, silver nitrate is obligatory, in

*Received for publication August 19, 1954. 
others not. In some, the obstetrician in charge of each hospital can make his own local rules. Berens writes:

In States which require the instillation of silver nitrate into the eyes after birth, the incidence of gonococcal ophthalmia has become almost negligible. In areas in which this procedure is not followed, the disease occurs in a high percentage of babies.

Berens further recommends that the eyelids should be cleansed, before opening, with 1 in 3000 bichloride of mercury, and that then 1 per cent. silver nitrate should be instilled. He adds:

Although silver nitrate is currently the most satisfactory preparation, the value of penicillin and the sulphonamides is under investigation and it is probable that silver nitrate will be entirely supplanted in the future.

England.-There has been a great deal of discussion between the Ministry of Health and the Central Midwives' Board. At the moment no prophylactic drops are recommended by the Ministry, and only thorough cleansing of the lids is to be carried out. Hospitals may however make their own local rules as in parts of America, and some still use silver nitrate, while some favour penicillin and some 20 per cent. sodium sulphacetamide. The Central Midwives' Board advises midwives to conform to local usage, but those going to work abroad are advised to use antibiotics.

Western Australia.-Gonorrhoea is not a common disease, and in the Perth School for the Blind there is no child who has suffered from ophthalmia neonatorum. It has therefore been felt that a review of the position is needed, since the King Edward Memorial Maternity Hospital has continued the routine use of prophylactic silver nitrate since its foundation. There is some dislike of the reaction caused by silver nitrate, but on the other hand, in view of the prevalence of penicillinresistant strains of staphylococci in this State, it is not considered wise to substitute routine antibiotics.

\section{Clinical Experiment}

It was therefore decided to try to settle the matter by clinical and bacteriological observation. Two groups of infants were involved. The first group (controls) comprised 569 live births at the King Edward Memorial Hospital, Perth, and these received no prophylactic drops, all that was done being cleansing of the lids at birth with swabs dipped in normal saline. The second group comprised 579 live births, and all these received, in addition to the cleansing of the lids, one drop of a 1 per cent. solution of silver nitrate (Table I).

The two groups were compared for incidence of discharge from the eyes after birth, for the day after birth on which the discharge was first noted, for the result of culture of the discharge, for the sensitivity of the organisms obtained to various antibiotics, and for the clinical course of the case.

It may be stated at the outset that in neither group did any case of severe purulent ophthalmia occur, and that the end result (clean eyes on discharge from hospital) was the same in every case in both groups (1,148 babies). There is, therefore, no absolute indication for use or disuse of silver nitrate, but during the course of the observations some interesting data were obtained, which bear out Crédés original contention of the value of silver nitrate as an antiseptic. However, should a case of purulent ophthalmia occur, its cure by modern methods is almost certain, and there is thus no actual need for prophylaxis. 
In all cases the routine procedure was to record the observation of any stickiness at all, and the day on which it was first noticed.

Comparison of Groups.-In the control group without silver nitrate, a hundred cases were noted out of 569 births (17.5 per cent.). The commonest time of onset was the 3rd day, the next commonest the 7 th day. This raises the question of the origin of the infection, and it was decided arbitrarily to take the 4th day as the limit for the appearance of discharge due to a natal infection from the birth canal. Stickiness appearing after this day was considered to be due to postnatal infection. If this is accepted, then forty of the hundred cases reported were natal in origin, and eight of these occurred within 24 hours.

In the group treated with silver nitrate, 72 cases were noted in 579 cases $(12.4$ per cent.). This in itself is a reduction in the number of sticky eyes. Of these 72 cases, 44 occurred on or before the 4 th day and 27 of these within 24 hours. This makes us wonder whether these 27 were actually infections rather than reactions to the silver nitrate. Of the 44,39 were cultured, and of these 23 showed no growth, two showed a white staphylococcus, non-haemolytic and coagulase negative, and the fourteen others showed potential pathogens. We can therefore consider 25 of these 44 to be due to silver nitrate reaction, which leaves us with only 47 infections in the whole group as opposed to an apparent 100 in the control group. Of these hundred, however, forty occurred in the first 4 days and only eight showed no growth, while nineteen showed potential pathogens, and the remaining nine showed a white staphylococcus, non-haemolytic and coagulase negative (Tables II and III).

In the control group, therefore, if these seventeen cases (eight " no growth" and nine Staph. alb. non-pathogenic) are discounted, nineteen cases showed potential pathogen infection, and in the silver nitrate group in the same period fourteen such cases appeared. This is not a vast difference and upholds one side of the argument, namely that silver nitrate causes an unnecessary amount of irritation of the eyes and in the absence of gonorrhoeal infection does very little else.

On the other hand, if we consider discharge from the eyes throughout the first 12 days of life as a whole, we find an incidence of 17.5 per cent. in the control group and of only 12.4 per cent. in the treated group. If in both groups we subtract the cases in the first 4 days which showed no pathogen on culture we find the figures become 14.5 per cent. in the control group and only 8.1 per cent. in the treated group. It therefore seems that the use of silver nitrate very definitely reduces the incidence of infection as distinct from discharge during the first 12 days of life. Tables I-III and the Figure show the incidence of discharge from the eyes and of true infection.

It is thus obvious that the clinical picture is different in the two groups, the control group showing a tendency for discharge to appear at any time during the first 12

TABLE I

INCIDENCE OF DISCHARGING EYES

\begin{tabular}{l|c|c|c}
\hline \multicolumn{1}{c|}{ Group } & $\begin{array}{c}\text { No. of } \\
\text { Live Births }\end{array}$ & $\begin{array}{c}\text { No. of } \\
\text { Discharging Eyes }\end{array}$ & Percentage \\
\hline Control & 569 & 100 & $17 \cdot 6$ \\
Treated $\left(\mathrm{AgNO}_{3}\right)$ & 579 & 72 & $12 \cdot 4$ \\
\hline
\end{tabular}


TABLE II

INCIDENCE OF PATHOGENS

\begin{tabular}{l|c|c|c}
\hline Group & $\begin{array}{c}\text { Total Discharging } \\
\text { Eyes }\end{array}$ & $\begin{array}{c}\text { No. of Pathogens } \\
\text { found in first 4 days }\end{array}$ & $\begin{array}{c}\text { Pathogens in first 12 } \\
\text { days as Percentage } \\
\text { of Live Births }\end{array}$ \\
\hline $\begin{array}{l}\text { Control } \\
\text { Treated }\end{array}$ & 100 & 17 & $\begin{array}{r}14 \cdot 6 \\
8 \cdot 1\end{array}$ \\
\hline
\end{tabular}

TABLE III

DAY DISCHARGE FIRST NOTED

\begin{tabular}{l|c|c|c|c|c|c|c|c|c|c|c|c|c}
\hline Day & 1 & 2 & 3 & 4 & 5 & 6 & 7 & 8 & 9 & 10 & 11 & 12 & $12+$ \\
\hline Control Cases & 8 & 12 & 13 & 7 & 11 & 10 & 12 & 5 & 8 & 5 & 3 & 1 & 4 \\
\hline Treated Cases $\dagger$ & 27 & 5 & 7 & 5 & 4 & 4 & 5 & 1 & 6 & 3 & 1 & 2 & - \\
\hline
\end{tabular}

days, with peaks at 3 and 7 days, and the treated group showing immediate reaction to the silver nitrate followed by a drop in incidence with a slight rise on the 9th day.

Clinical Conditions.-The picture is further complicated by the fact that in many cases the condition was not a conjunctivitis only. In very few cases of either group was there any severe infection of the ocular conjunctiva, but in most there was slight redness of the palpebral conjunctiva of the lower lid. In the control group there

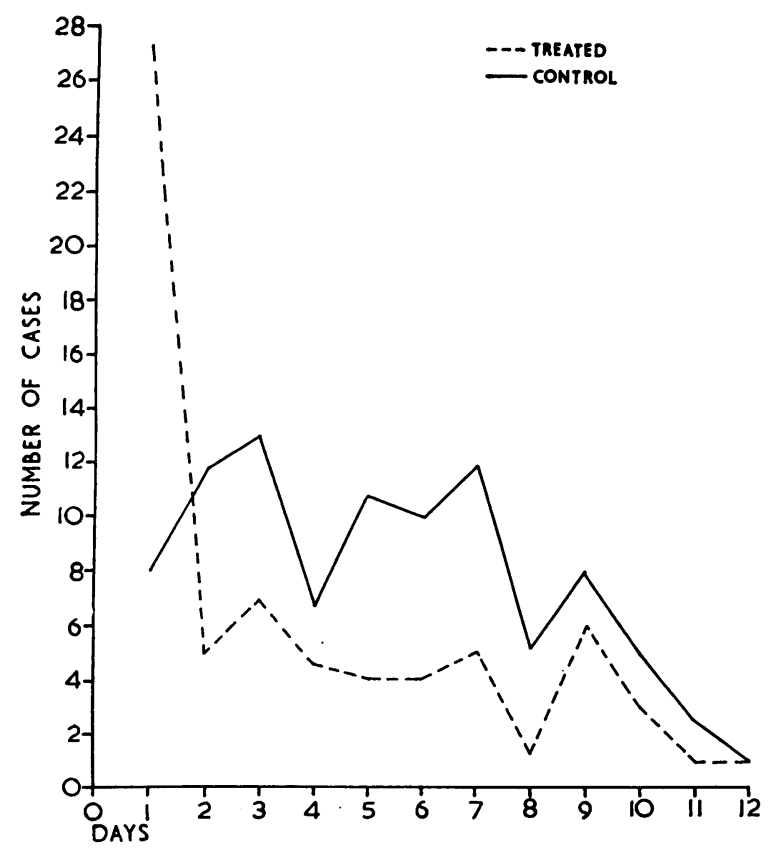

FIGURE.-Relationship between number of cases and first day of discharge in treated and control groups. were four cases of blocked tear duct, in the treated group none. In both groups there were a number of cases showing small pustules on the lids, especially the lower, and small septic skin eruptions on the body occasionally also. In the control group fourteen cases had skin pustules, in the treated group thirteen cases. In the control group there were also four cases of fairly severe conjunctivitis requiring careful treatment and taking up to 12 days to clear completely. In the treated group there was no severe conjunctivitis, in spite of the bacteriological findings to be described later, which appear worse than those of the untreated group. This may point to a greater resistance of the tissues in the 
treated group, so that the more severe infections are not manifested clinically and the minor infections do not occur. The similar incidence of skin infections in the two groups seems to point to a local resistance in the eyes of the treated group.

Bacteriological Findings. -92 cases were cultured in the control group and 64 in the treated group. The main differences in the findings in the two groups are the greater number of sterile cultures in the treated group (showing that the discharge is largely due to reaction to the silver nitrate) and the greater number of nonpathogenic white staphylococci grown in the untreated group, which is rather to be expected. An unexpected finding is the greater number of double infections in the treated group; the significance of this is doubtful. Table IV shows the incidence of various types of organism in the two groups.

TABLE IV

ORGANISMS GROWN

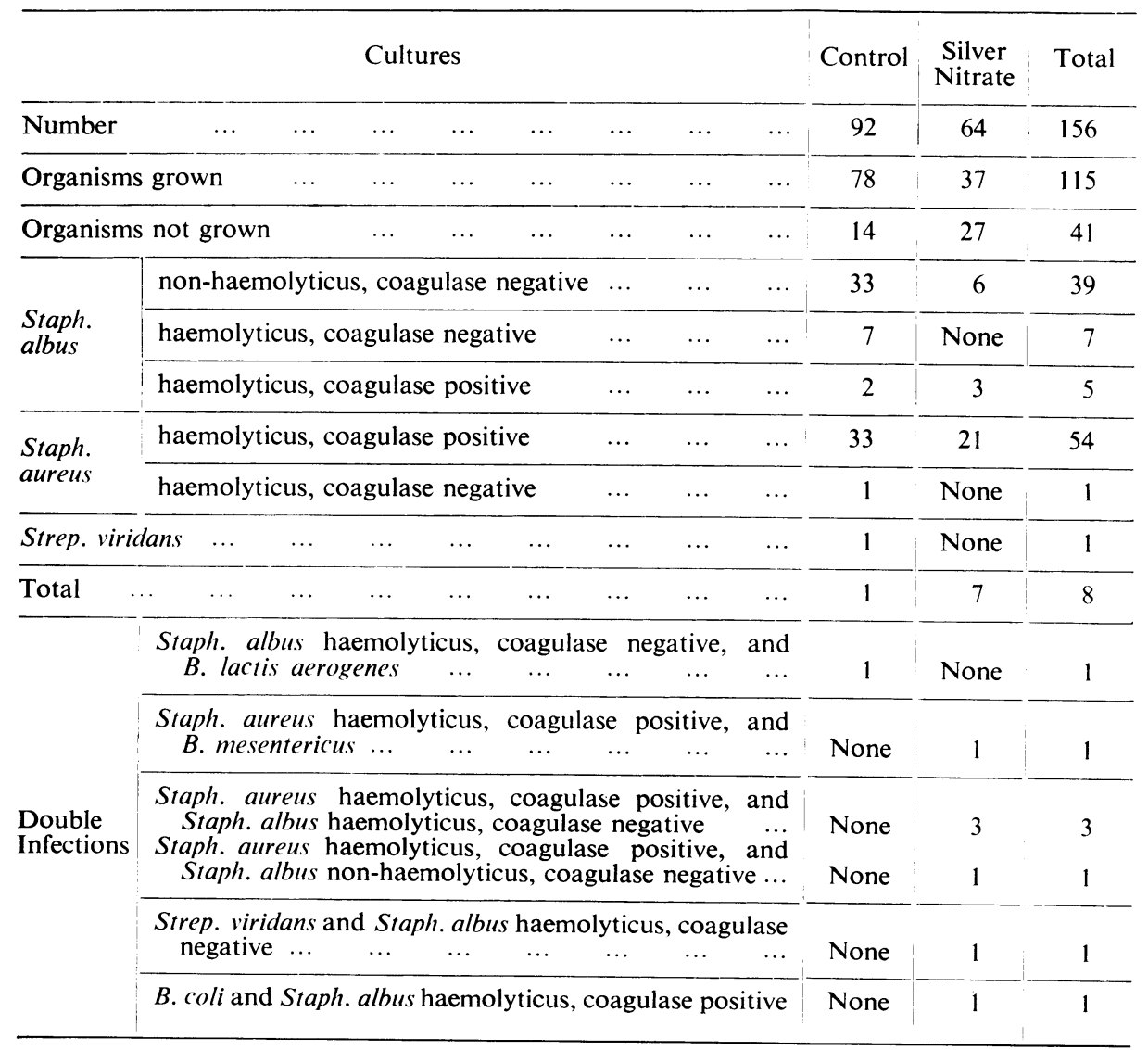

Table V (opposite) shows the day on which each infection appeared (where known) in both groups. The smear was taken on the first day in every case. 
TABLE V

DAY ORGANISMS FIRST FOUND

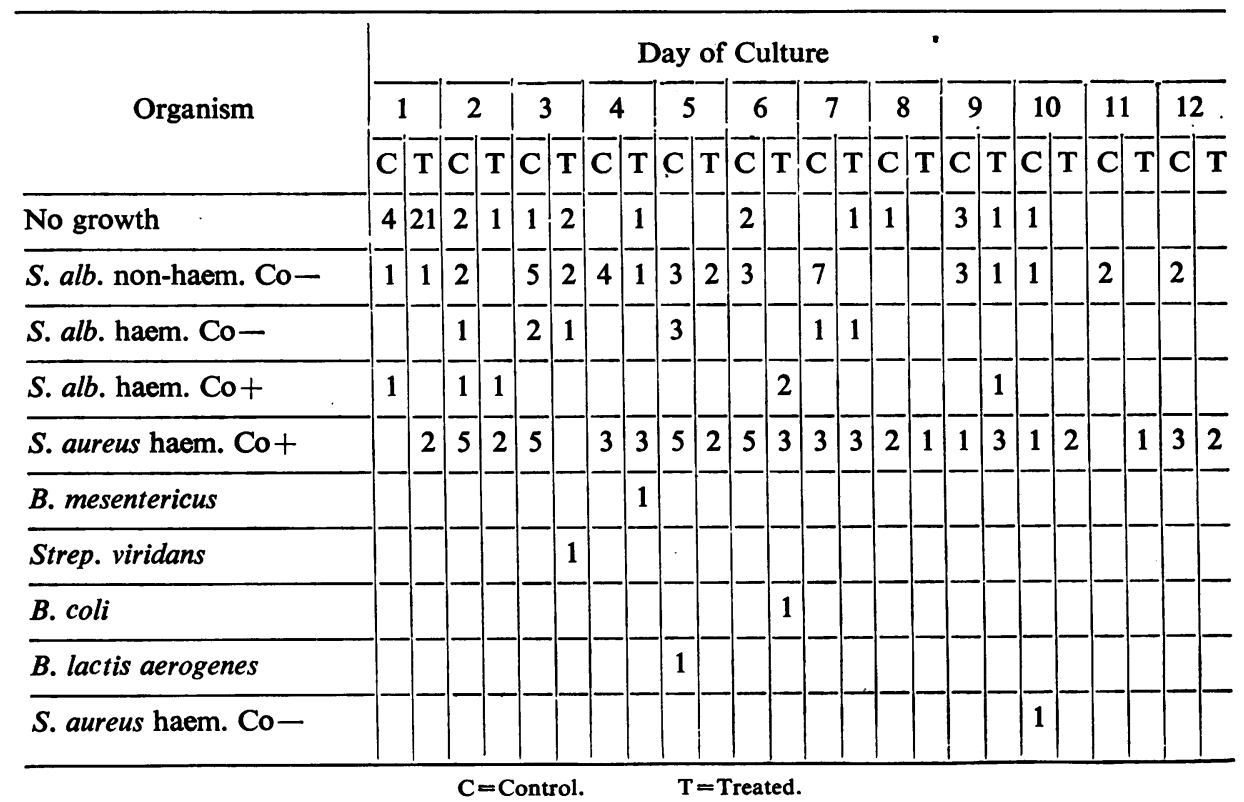

Sensitivity.-The question of the sensitivity of the various organisms to the more usual antibiotics was investigated in a certain number of cases, though not in all. It was not considered necessary to test more than a sample of the white staphylococci, and not all the organisms tested were tried against all the antibiotics.

Table VI (overleaf) shows that only streptomycin gave a universal result, no organism tested against it being negative. Aureomycin ran it close, with two negatives (both Staph. aureus from the treated group). Chloramphenicol gave 5 , terramycin 10 , sulphadiazine 29 , and penicillin 35 negatives, the majority in the pathogenic Staphylococcus aureus group. This demonstrates very well the futility of the search for a universally protective drug, unless it is decided to use streptomycin exclusively. This would have the disadvantage of neutralizing actual birth infections only, which are not, in this hospital and at the present time, at all dangerous. It would not be likely to have a prolonged protective effect.

Penicillin and sulphadiazine are of little use and it is suggested that these substances should not be used in routine treatment. Unless a sensitivity test can be done, streptomycin is the antibiotic of choice in every case. From practical experience, however, it is usually unnecessary as clinical results show.

\section{Clinical Course and Results}

When an eye was found to be " sticky", the procedure was to take a smear and culture and, before receiving the report, to treat with frequent cleansing of the lids with saline only. If the discharge did not respond within 4 days, sodium sulphacetamide drops were used 2-hourly, and aureomycin cream 
TABLE VI

DEGREE OF SENSITIVITY

\begin{tabular}{|c|c|c|c|c|c|c|c|c|c|c|c|c|c|}
\hline & \multirow{3}{*}{$\begin{array}{l}\text { Degree of } \\
\text { Antibiotic } \\
\text { Sensitivity }\end{array}$} & \multicolumn{6}{|c|}{ S. albus } & \multirow{2}{*}{\multicolumn{4}{|c|}{$\frac{\text { S. aureus }}{\text { haem. }}$}} & \multirow{3}{*}{$\begin{array}{l}\text { Strep. } \\
\text { viridans }\end{array}$} & \multirow{3}{*}{$\begin{array}{c}B . \\
\text { coli }\end{array}$} \\
\hline & & \multicolumn{2}{|c|}{$\begin{array}{c}\text { non- } \\
\text { haem. }\end{array}$} & \multicolumn{4}{|c|}{ haem. } & & & & & & \\
\hline & & \multirow{2}{*}{$\frac{\mathrm{Co} .}{\mathrm{C}}$} & \multirow{2}{*}{$\frac{\text { neg. }}{T}$} & \multirow{2}{*}{$\frac{\text { Co. }}{\mathrm{C}}$} & \multirow{2}{*}{$\frac{\text { neg. }}{T}$} & \multirow{2}{*}{$\frac{\text { Co. }}{\mathrm{C}}$} & \multirow{2}{*}{$\frac{\text { pos. }}{T}$} & \multirow{2}{*}{$\frac{\text { Co. }}{C}$} & \multirow{2}{*}{$\frac{\text { pos. }}{T}$} & \multirow{2}{*}{$\frac{\text { Co. }}{\text { C }}$} & \multirow{2}{*}{$\frac{\text { neg. }}{T}$} & & \\
\hline & & & & & & & & & & & & $T$ & $\mathrm{~T}$ \\
\hline Penicillin & $\begin{array}{r}- \\
+ \\
++ \\
+++\end{array}$ & $\begin{array}{r}2 \\
3 \\
2 \\
-\end{array}$ & $\begin{array}{l}2 \\
1 \\
2 \\
1\end{array}$ & \begin{tabular}{l|l}
- & \\
3 \\
-
\end{tabular} & $\frac{1}{1}$ & & $\begin{array}{l}2 \\
1 \\
-\end{array}$ & $\begin{array}{l}13 \\
25 \\
2\end{array}$ & $\begin{array}{r}14 \\
8 \\
4 \\
+\quad 2\end{array}$ & $\frac{-}{1}$ & $\begin{array}{l}- \\
- \\
-\end{array}$ & $\frac{-}{1}$ & $\begin{array}{l}- \\
\overline{-} \\
-\end{array}$ \\
\hline Streptomycin & $\begin{array}{r}- \\
+ \\
++ \\
+++\end{array}$ & $\begin{array}{c}- \\
6 \\
1\end{array}$ & $\overline{-}$ & \begin{tabular}{c|}
- \\
5 \\
1
\end{tabular} & $\frac{-}{3}$ & & $\begin{array}{l}- \\
2 \\
-\end{array}$ & $\begin{array}{r}-11 \\
21 \\
3\end{array}$ & $\begin{array}{r}\overline{4} \\
20 \\
2\end{array}$ & $\bar{z} \overline{-}$ & $\frac{-}{1}$ & $\frac{-}{1}$ & $\overline{1}$ \\
\hline Aureomycin & $\begin{array}{r}- \\
+ \\
++ \\
++\end{array}$ & $\begin{array}{r}- \\
2 \\
-\end{array}$ & $\begin{array}{l}\overline{3} \\
-\end{array}$ & $\begin{array}{l}\overline{2} \\
2 \\
2\end{array}$ & $\frac{-}{3}$ & & $\frac{-}{2}$ & $\begin{array}{r}- \\
20 \\
6\end{array}$ & $\begin{array}{r}2 \\
19 \\
3 \\
3\end{array}$ & $\begin{array}{l}\overline{-} \\
\overline{1}\end{array}$ & $\begin{array}{l}- \\
-\end{array}$ & $\frac{-}{1}$ & $\frac{1}{-}$ \\
\hline Chloramphenicol & $\begin{array}{r}- \\
+ \\
++ \\
+++\end{array}$ & $\begin{array}{r}- \\
4 \\
-\end{array}$ & $\frac{\overline{2}}{1}$ & $\begin{array}{l}\overline{1} \\
3 \\
2\end{array}$ & $\frac{\overline{2}}{1}$ & & $\begin{array}{l}1 \\
2 \\
-\end{array}$ & $\begin{array}{r}- \\
22 \\
4\end{array}$ & $\begin{array}{r}5 \\
16 \\
3 \\
2\end{array}$ & $\frac{-}{1}$ & $\begin{array}{l}\overline{1} \\
-\end{array}$ & $\frac{-}{1}$ & $\begin{array}{r}1 \\
- \\
-\end{array}$ \\
\hline Terramycin & $\begin{array}{r}- \\
+ \\
++ \\
+++\end{array}$ & $\begin{array}{r}- \\
3 \\
-\end{array}$ & $\begin{array}{r}\overline{2} \\
2 \\
-\end{array}$ & $\frac{-5}{-}$ & $\begin{array}{l}-3 \\
-\end{array}$ & & \begin{tabular}{l|}
1 \\
1 \\
1 \\
-
\end{tabular} & $\begin{array}{r}2 \\
25 \\
2 \\
\end{array}$ & $\begin{array}{r}6 \\
15 \\
2 \\
-\end{array}$ & $\begin{array}{c}\overline{-} \\
-1 \\
-\end{array}$ & $\frac{1}{-}$ & $\begin{array}{c}\overline{1} \\
-\end{array}$ & $\begin{array}{l}1 \\
- \\
-\end{array}$ \\
\hline Sulphadiazine & - & - & 1 & - & 1 & & $\frac{3}{-}$ & $\begin{array}{l}5 \\
1\end{array}$ & $\frac{18}{-}$ & & & - & 1 \\
\hline $\begin{array}{l}\text { Sodium sulpha- } \\
\text { cetamide } 20 \\
\text { per cent. }\end{array}$ & - & $\overline{1}$ & 1 & $\overline{1}$ & $\overline{-}$ & & - & $\begin{array}{l}6 \\
3\end{array}$ & 1 & & & - & 1 \\
\hline
\end{tabular}

was rubbed on if the skin was also infected. Every case cleared satisfactorily in both groups, but, on the whole, the control group took rather longer to become clear. Thus in 22 cases in the untreated group the infection lasted longer than 5 days, as against six cases in the treated group. The majority in both groups cleared with no treatment other than saline swabbing. Thus very little correlation was apparent between the bacteriological findings and the clinical course and response to treatment. Indeed, a case bacteriologically negative to sulphacetamide was often clear before the report came back. Clinical judgement, therefore, still remains the best guide to treatment and prognosis, and cleanliness still appears the surest road to cure in our present mild type of case. Silver nitrate would appear unnecessary but not ineffective as a routine prophylactic, though if the dislike of the initial reaction can be overcome it will obviate the need for subsequent treatment in a large number 
of cases. It need not be recommended for use in an efficient hospital in a country with a low incidence of gonorrhoea, but should still be considered as desirable in primitive conditions among infected populations.

\section{Summary}

(1) The incidence, type, and course of ocular infections in the new born was investigated in 1,148 live births at the King Edward Memorial Hospital, Perth, Western Australia.

(2) The infants were divided into two groups. The controls received no prophylactic treatment at birth, other than cleaning the lids; the other group received one drop of 1 per cent. silver nitrate.

(3) Discharge from the eyes within the first 12 days occurred in one hundred of the control group of 569 live births, and in 72 of 579 live births in the treated group.

(4) No severe case occurred in either group.

(5) Cases in the treated group cleared up quicker than in the control group.

(6) In the treated group the discharge appeared early; it was largely due to reaction to the silver nitrate and was sterile.

(7) Streptomycin sensitivity was positive in all the organisms tested. Penicillin and sulphadiazine gave the worst results.

(8) It is demonstrated that the old teaching about silver nitrate is correct, but it is suggested that its use is unnecessary in a modern hospital and in a population in which gonorrhoea is rare.

I wish to thank the members of the nursing and laboratory staff of the King Edward Memorial Hospital for all the work they did in keeping the records, without which the investigation could not have been made. 